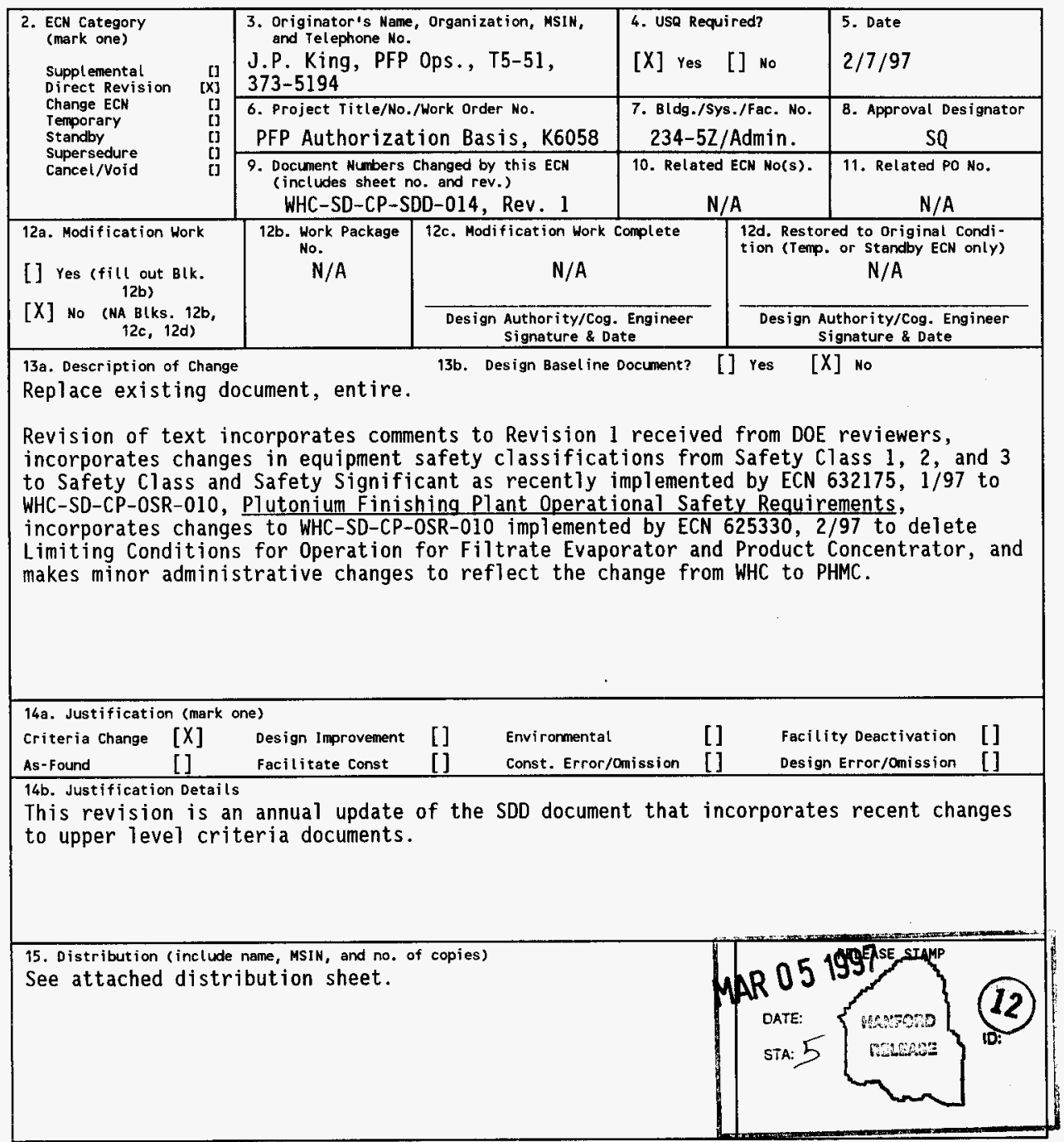




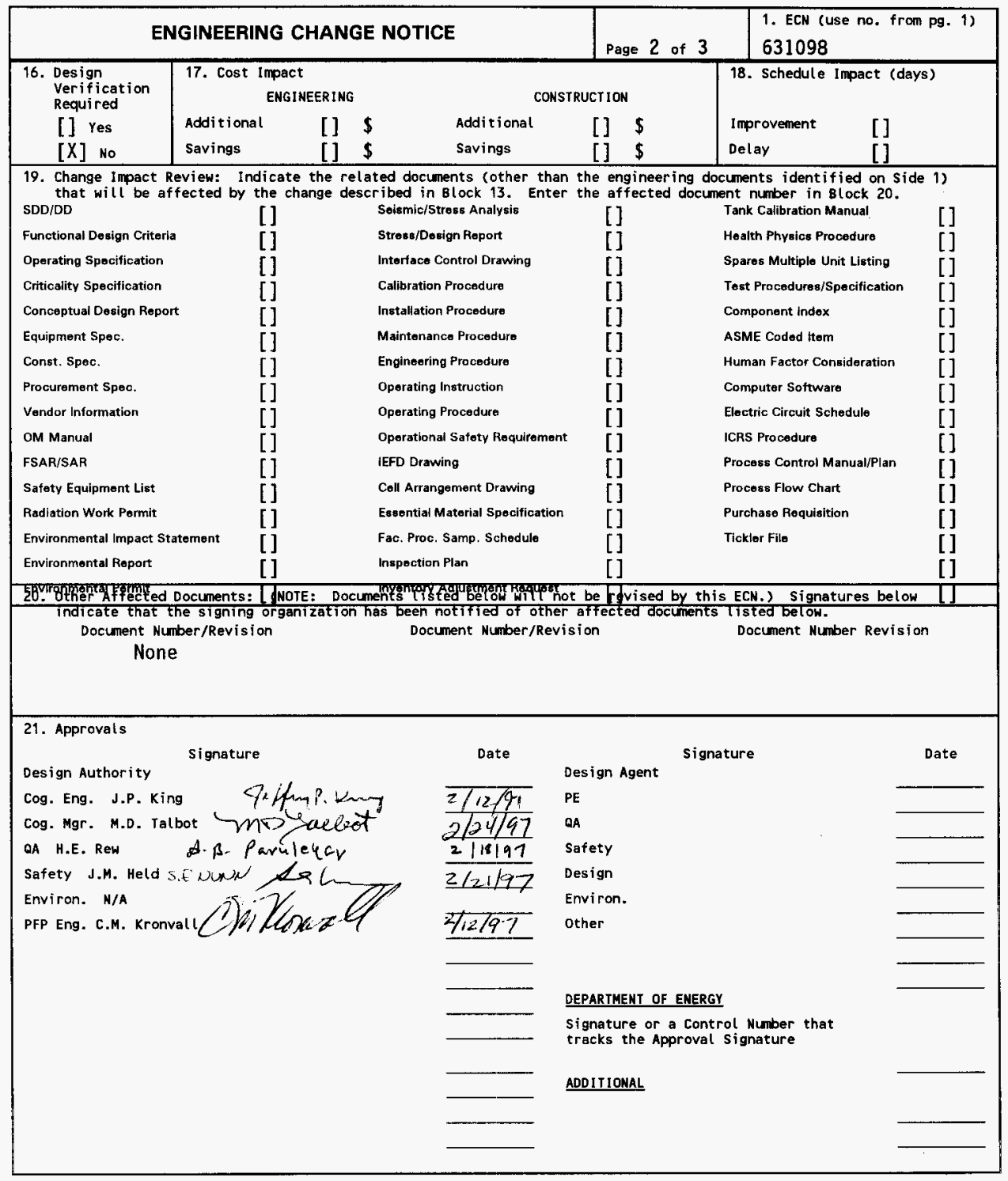




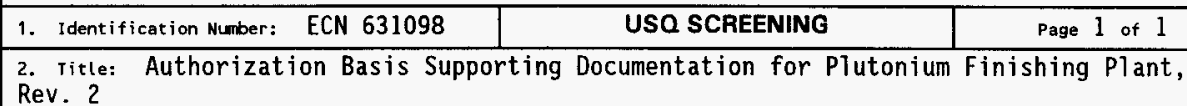

1. Does the proposed change or occurrence represent a change to the facility or procedures as described in the Authorization Basis?
[] N/A
[X] No
[] Yes/Maybe

BASIS: The revision to WHC-SD-CP-SDD-014 incorporates DOE review comments made to Rev. 1 of the document that are administrative in nature, incorporates recent changes made to Appendix $B$ and $C$ of WHC-SD-CP-OSR-010, Plutonium Finishing Plant Operational Safety Requirements by ECN 632175 which implements change in safety system classification, and deletes reference to LCOS 3.4.1 and 3.4.2 for the PRF Filtrate Evaportor and Product Concentrator deleted (and USQ Evaluated) from 0SR-010 by ECN 625330, and other minor administrative changes. Therefore, the question is answered NO.

2. Does the proposed change or occurrence represent conditions that have not been analyzed in the Authorization Basis?
[] $\mathrm{N} / \mathrm{R}$
[X] No
[] Yes/Maybe

Basis: The revision to SDD-014 does not change any condition described in the Authorization Basis.

3. Does the proposed change represent a test or experiment NOT described in the Authorization Bas is that may affect the safe operation of the facility?

[X] N/A [] No [] Yes/Maybe

Basis: No tests or experiments are involved with the SDD-014 change.

4. Does the proposed change or occurrence represent a change to the Technical Safety Requirements or a reduction in the margin of safety defined in the Technical Safety Requi rements?
[] $N / A$
$[X]$ No
[] Yes/Maybe

Basis: The change to SDD-014 is in response to changes made in the OSR document and other administrative items and does not involve any margin of safety. The change to SDD-014 does not required any additional changes to the OSR documents.

USQE \#1 Jeffry P. King

(Print Name)

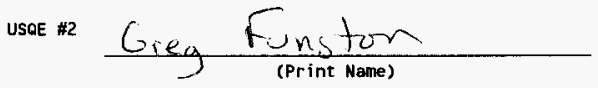

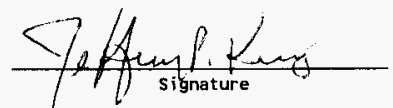

Date:
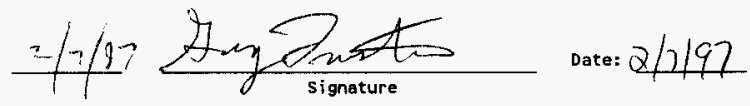

If there is a YES/MAYBE response to questions 1, 2, 3, or 4, then a USQ Evaluation must be completed.

The following guidance should be considered when completing this screening. This guidance should not be considered allinclusive; additional factors may need to be considered depending on the nature of the proposed change.

Does the proposed change:

1) Modify, add, or delete a safety class function of a structure, system or component stated in the authorization basis?

2) Alter the design of a structure, system or component as described in the authorization basis?

3) Modify, add, or delete the description of operation, operating environment, or analyses of any system or component described in the authorization basis?

4) Modify, add, delete or conflict with any of the design bases stated in the authorization basis?

5) Conflict with the principle or general design criteria stated in the authorization basis?

6) Modify, add, or delete any plant design features described in the authorization basis?

7) Modify, add, or delete a flow diagram or facility drawing provided in the authorization basis?

8) Create the potential for new system or component interactions (e.9., seismic, electrical breaker coordination)? 


\section{Authorization Basis Supporting Documentation for Plutonium Finishing Plant}

J. P. King

Babcock and Wilcox Hanford Company, Richland, WA 99352

U.S. Department of Energy Contract DE-AC06-96RL13200

EDT/ECN: 631098

Org Code: 15310

B\&R Code: EW7002010
UC: 610

Charge Code: $\mathrm{K} 6058$

Total Pages: 25

Key Words: Authorization Basis, Safety Envelope, OSR, SAR, FSAR, USQ Basis, PFP

Abstract: This document is an upper tier document that describes the general structure of the Authorization Basis and Safety Envelope contained in WHC-SD-CP-SAR-021, Plutonium Finishing Plant Final Safety Analysis Report and WHC-SD-CP-OSR-010, Plutonium Finishing Plant Operational Safety Requirements. This document provides a description of plant systems, structures, and components (SSCs) that are important to safety and is a guide to a series of System Design Description (SDD) documents that contain detailed information on safety envelope systems and a means to OSR compliance.

TRADEMARK DISCLAIMER. Reference herein to any specific commercial product, process, or service by trade name, trademark, manufecturer, or otherwise, does not necessarily constitute or imply its endorsement, recomendation, or favoring by the United States Government or any agency thereof or its contractors or subcontractors.

Printed in the United States of America. To obtain copies of this doclment, contact: Document Control Services, P.O. Box 950, Mailstop H6-08, Richland WA 99352, Phone (509) 372-2420; Fax (509) 376-4989.
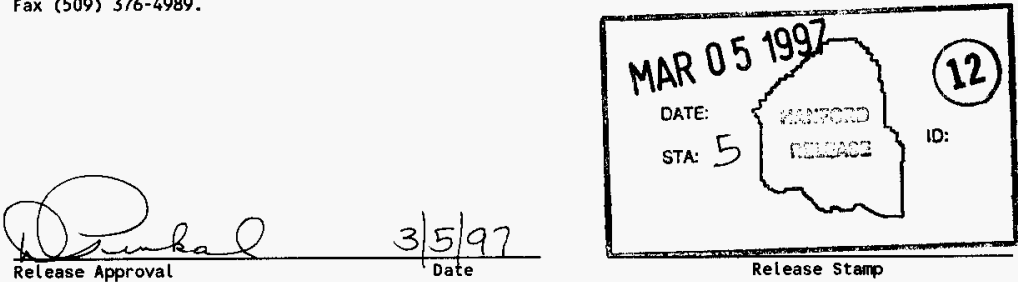

\section{Approved for Public Release}


(2) Title

Authorization Basis Supporting Documentation for Plutonium Finishing Plant CHANGE CONTROL RECORD

\begin{tabular}{|c|c|c|c|}
\hline \multirow{2}{*}{ (3) Revision } & \multirow{2}{*}{ (4) Description of Change - Replace, Add, and Delete Pages } & \multicolumn{2}{|c|}{ Authorized for Release } \\
\hline & & (5) Cog. Engr. & (6) Cog. Mgr. Date \\
\hline 0 & (7) Initial Release, EDT 140650 & & $2 / 9 / 93$ \\
\hline Oa & Page Changes, Pages $14,19,20$, ECN 607940 & & $8 / 1 / 94$ \\
\hline 1 & $\begin{array}{l}\text { Complete Revision ECN } 625327 \text {. Incorporate } \\
\text { ECN \#S } 607939 \text {, } 607940 \text {. Update text and } \\
\text { graphics to reflect current plant } \\
\text { Configuration as documeted in WHC-SD-CP- } \\
\text { SAR-021, Plutonium Finishing Plant Final } \\
\text { Safety Analysis Report, 1/1995; and WHC-SD- } \\
\text { CP-OSR-010, Plutonium Finishing Plant } \\
\text { Operational Safety Requirements, Rev. 0, } \\
5 / 1994 \text {. }\end{array}$ & & $11 / 3 / 95$ \\
\hline $\mathrm{RS}^{2}$ & $\begin{array}{l}\text { Complete Revision ECN } 631098 \text {. Update text } \\
\text { and graphics to reflect current plant } \\
\text { configuration as documeted in WHC-SD-CP- } \\
\text { SAR-02l, Plutonium Finishing Plant Final } \\
\text { Safety Analysis Report, } 1 / 1995 ; \text { and WHC-SD- } \\
\text { CP-OSR-010, Plutonium Finishing Plant } \\
\text { Operational Safety Requirements, Rev. 0-F, } \\
\text { 2/1997. }\end{array}$ & $3 / 5$ & $n_{15}^{-19}$ \\
\hline & & & \\
\hline & & & \\
\hline & & & \\
\hline & & & \\
\hline & & & \\
\hline & & & \\
\hline & & & \\
\hline & & & \\
\hline & & & \\
\hline & & & \\
\hline & & & \\
\hline & & & \\
\hline & & & \\
\hline & & & \\
\hline & & & \\
\hline & & & \\
\hline & & & \\
\hline & & & \\
\hline & & & \\
\hline
\end{tabular}




\section{Table of Contents}

1.0. Introduction .................... 4

2.0. Authorization Basis Definition Process . . . . . . . . . 6

2.1. Identified Events . . . . . . . . . . . . . . . . 8

2.2. Preventive or Mitigative Functions and Features . . . . . . . 11

2.3. Identification of Safety Envelope SSCs ............ 15

3.0. References ....................... 24 


\subsection{Introduction}

The identification and definition of the authorization basis for the Plutonium Finishing Plant (PFP) facility and operations are essential for compliance to DOE Order 5480.21, Unreviewed Safety Questions. The authorization basis, as defined in the Order, consists of those aspects of the facility design basis, i.e., the structures, systems and components (SSCS) and the operational requirements that are considered to be important to the safety of operations and are relied upon by DOE to authorize operation of the facility. These facility design features and their function in various accident scenarios are described in WHC-SD-CP-SAR-021, Plutonium Finishing Plant Final Safety Analysis Report (FSAR), Chapter 9, "Accident Analysis." Figure 1 depicts the relationship of the Authorization Basis to its components and other information contained in safety documentation supporting the Authorization Basis. The PFP SSCs that are important to safety, collectively referred to as the "Safety Envelope" are discussed in various chapters of the FSAR and in WHC-SD-CP-0SR-010, Plutonium Finishing Plant Operational Safety Requirements. Other documents such as Criticality Safety Evaluation Reports (CSERs) address and support some portions of the Authorization Basis and Safety Envelope.

The other aspect of the Authorization Basis, the maintenance of the Safety Envelope via administrative requirements is also addressed, in general terms, in several of the FSAR chapters, in contractor policy and directive manuals and, more definitively, in the Administrative Control (AC) section of the OSRs.

The purpose of this document is to provide a guide to the series of system design description documents (SDDs) that support the Safety Envelope, a definitive description of the safety related SSCS that define the PFP Safety Envelope, and the safety related operational requirements (1imits, controls, and procedures) that are specified to ensure maintenance of the Safety Envelope. SDDs are also the essential references for use in evaluating changes and discoveries for potential unreviewed safety questions (USQ). 


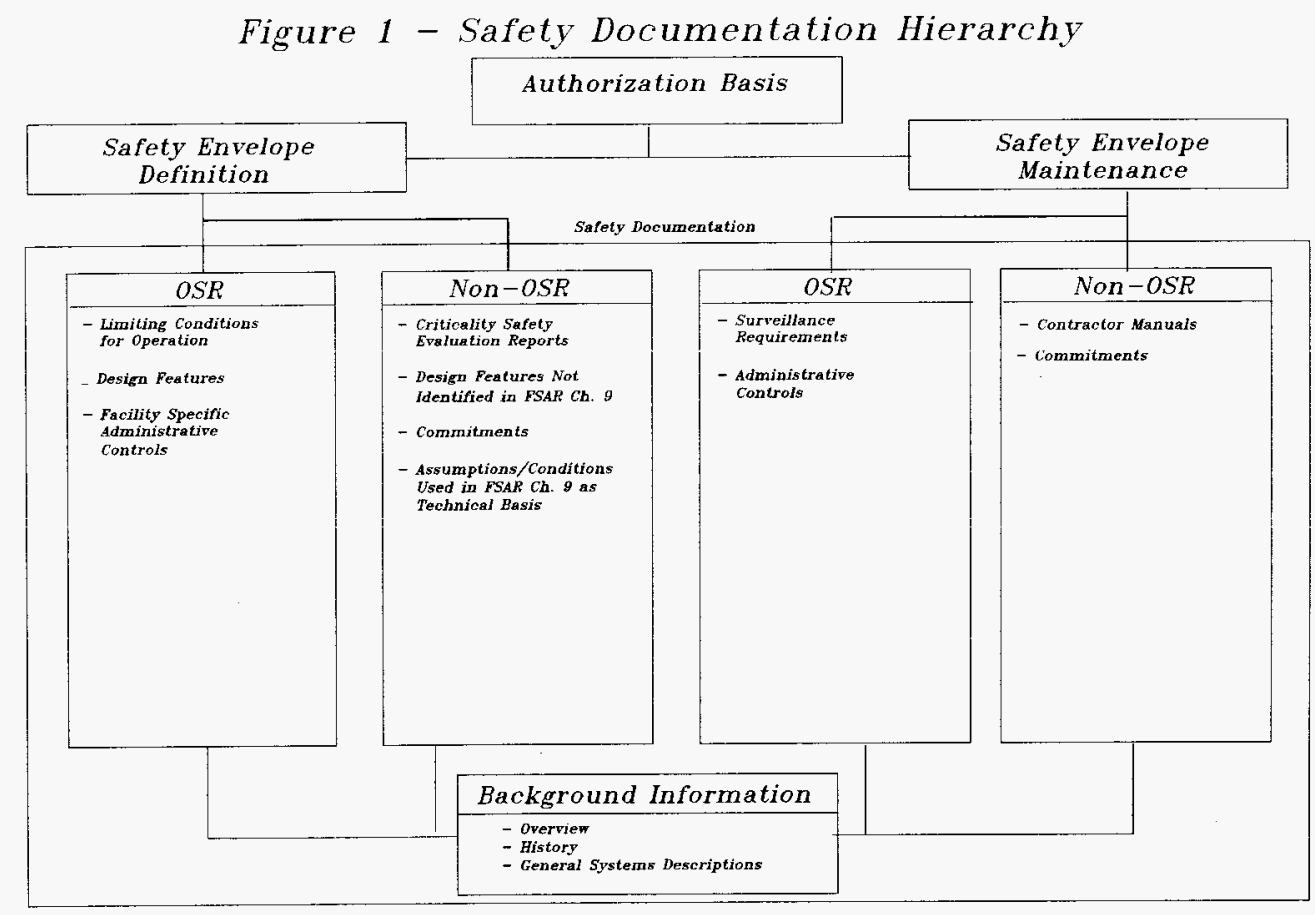


Section 2 of this document describes the process involved in the definition of the Safety Envelope, including the rationale for selecting the Safety Envelope SSCs. The SDDs for each of the identified safety SSCs are described and referenced in Section 2.3. The SDDs provide the Safety Envelope definition for PFP.

\subsection{Authorization Basis Definition Process}

The Authorization Basis, as discussed previously, consists of those aspects or features of the facility design and operational requirements that are important to facility and operations safety. This same concept is referred to as the facility "Safety Basis" in DOE Order 5480.23, Nuclear Safety Analysis Reports and is defined as "the combination of information relating to the control of hazards at a nuclear facility (including design, engineering analysis, and administrative controls) upon which DOE depends for its conclusion that activities at the facility can be conducted safely". Both the 5480.21 term and the 5480.23 term are used interchangeably and are defined more simply as the combination of engineered design features and administrative/operational control requirements necessary to ensure facility operations safety.

Prior to issuance of the new requirements for SAR preparation and content in DOE 5480.23 , the Safety Basis was required to address only SSCs and administrative controls necessary to ensure safety of the public and on-site, non-facility personnel. These concerns are addressed in FSAR Chapter 9 and the OSRs. DOE 5480.23, however, requires safety analyses and Technical Safety Requirements (TSRs) ${ }^{1}$ to consider protection of facility personnel as well as the public and other on-site personnel. 
PFP has submitted a compliance plan to the DOE documenting the equivalency of the current FSAR, when combined with other established safety programs, to the content requirements of DOE 5480.22 and 5480.23 . For this reason, the Safety Envelope discussed in the following paragraphs is broader in scope than the PFP Authorization Basis basis explicitly described in the FSAR and OSR.

The PFP Safety Envelope consists of those SSCs that provide preventive and mitigative functions for protection of the public, onsite personnel, and facility workers. As discussed previously, the Safety Envelope SSCs are identified in FSAR Chapter 9, the OSRs, and in other significant safety documentation such as CSERs. Consistent with the graded approach to classification of safety systems and contained in DOE Order 5480.23, the PFP Safety Envelope is comprised of two tiers of importance. The upper tier is the subject of OSR Limiting Conditions for Operations (LCOS) and consists of the external confinement features and those items which prevent a nuclear criticality. These are Safety Class items collectively referred to as the Safety Class safety envelope (SC Safety Envelope). The other tier of importance deals with protection of the facility worker population and includes the criticality alarm system (CAS). The CAS is subject to a LCO in accordance with DOE 5480.22. The remaining items do not have associated OSRs and are either Safety Signficant items or safety function items required by other safety programs. They protect facility workers by providing controls on confinement within the facility and the protection of personnel by notification of abnormal or hazardous conditions which warrant evacuation from hazardous conditions within the facility. These items collectively are referred to as the Safety Significant Safety Envelope (SS Safety Envelope). 
The identification and selection process, shown schematically in Figure 2 , involves the following steps:

- Identification of accidents and abnormal operations of safety concern;

- Definition of preventive and/or mitigative functions;

- Identification of the PFP SSCs that provide the required functions; and

- Development of SDD documents for PFP safety envelope SSCs.

\subsection{Identified Events}

The accidents and abnormal operations of safety concern are identified in FSAR Chapter 9. FSAR Section 9.1 discusses the events that could impact the safety of the facility personnel. Section 9.2 discusses the events that could impact the safety of the public and on-site, non-PFP personnel. Eight events were identified that were of sufficient significance to be of safety concern. These are described as follows:

- Seismic Event. The design basis earthquake (DBE) for high hazard nonreactor nuclear facilities at the Hanford Site is defined in the Hanford Standard Design Criteria (RL 1989) as an earthquake having a horizontal ground acceleration of $0.20 \mathrm{~g}$. The seismic analyses for the PFP buildings, summarized in Chapter 5 of the FSAR, concluded that all buildings, except 232- $Z$ and 241-Z, would remain intact after a DBE. Within these two buildings some localized "non-linear deformations" possibly leading to breaching of the confinement barriers could be expected. 


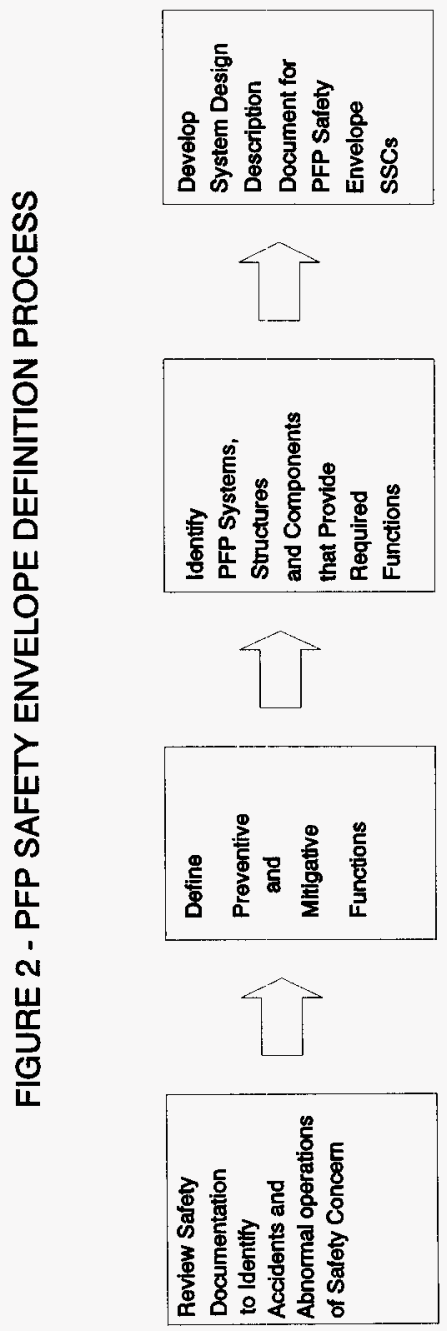


- Strong Wind. The design basis wind for high hazard nuclear facilities at the Hanford Site is defined in SDC 4.1 (RL 1989) as a 90 miles per hour wind. All PFP buildings have been analyzed and all, except Building 2734- $Z$, were determined to be resistant the design basis wind.

- Aircraft/Missiles. The probability of an aircraft crashing into PFP was analyzed in accordance with the criteria referenced in NUREG 75/087 and determined to be incredible. The only instance of significant hazard from other missiles was penetration of Building 2734-ZL by a wind-driven missile (PFP FSAR, Section 5.2.1). This building is no longer in use and the hydrogen fluoride has been removed from the building

- Explosions. The accident analysis in FSAR Section 9.2.1 identifies four different types of explosions with potentially sufficient energy to possibly disperse plutonium to onsite and offsite people. Only one type, however, explosion of nitrated organic compounds, was judged to be credible or of concern to the PFP operations. Specific situations which could result in an explosion of nitrated organic compounds are more fully described in FSAR Section 9.2.1. Propane explosions within PFP buildings are analyzed in FSAR Section 9.2.1F.

- Fire. FSAR Section 9.2.2 determined that a fire in the RMC Line gloveboxes is the design basis fire for the PFP. The analysis also determined it would be incredible for this, or any other fire, to be large enough to result in an unacceptable release of $\mathrm{Pu}$ to the environment. The consequences of a fire causing a breach of confinement within the building are high enough to be of concern with respect to safety of facility personnel. FSAR Section 9.2.2D. addresses a fire involving Transuranic (TRU) containing waste drums stored outside. The waste drum fire analys is establishes limits on the amount of Pu equivalent TRU that can be stored in drums outside within the PFP fence line. 
- Nuclear Criticality. Specific event scenarios for nuclear criticalities are not developed in FSAR Chapter 9, as the possibilities are almost too numerous to list. Rather, generic events involving solid Pu metal, Pu powder, and $\mathrm{Pu}$ solutions are described. The combination of engineered design features, strict administrative controls, and training at PFP in criticality safety ensures the probability of a criticality occurring during normal operations is very low. As discussed in FSAR Section 9.2.3, the more likely scenario would occur during actions taken to recover from some off-normal or unusual condition.

- Spills/Pressurization. Spills or pressurization of containers of plutonium bearing materials, in either powder or liquid form, are categorized as abnormal operations in FSAR Sections 9.1.1 through 9.1.4. This categorization is consistent with the FSAR definition of abnormal operations as those events that "address radiological consequences to plant personne1."

- Ventilation Upsets. Ventilation upsets at the PFP, as described in FSAR Section 9.1.7, are categorized as either building pressurization events, building depressurization events, or complete loss of ventilation. None of these events, by themselves, result in safety concerns for the public or onsite non-facility personnel.

\subsection{Preventive or Mitigative Functions and Features}

Definition of the required preventive or mitigative functions and the design features that provide these function follows logically from the identification of the accidents and abnormal operations. The three preventative or mitigative functions associated with the identified events are confinement, preservation of confinement, and communications. 
The PFP SSCs which provide these preventative or mitigative features constitute the Safety Envelope and are discussed in Section 2.3. Detailed descriptions of the configuration of each system or subsystem have been developed and are contained in system design documents (SDDs) as shown in Figure 3. The SDDs include the safety classification of the system, a list of the components of the system or Essential Drawings containing the components, and descriptions of the physical and functional characteristics of the components. Information sources for selecting the Safety Envelope SSCs identified in the SDDs include:

- PFP FSAR, WHC-SD-CP-SAR-021;

- Chapter 4 (safety classification)

- Chapters 5 through 8 (individual system descriptions)

- Chapter 9 (accident analyses and safety functions of systems)

- OSRs, WHC-SD-CP-OSR-010;

- $\quad$ Operating Specification Documents (OSDS);

- Essential Drawings;

- Piping and Instrument Diagrams (P\&IDs);

- Instrument and Engineering Flow Diagrams (IEFDs);

- Installation Layout Drawings; and

- Equipment Arrangement Drawings. 
Figure 3. PFP Authorization Basis Development

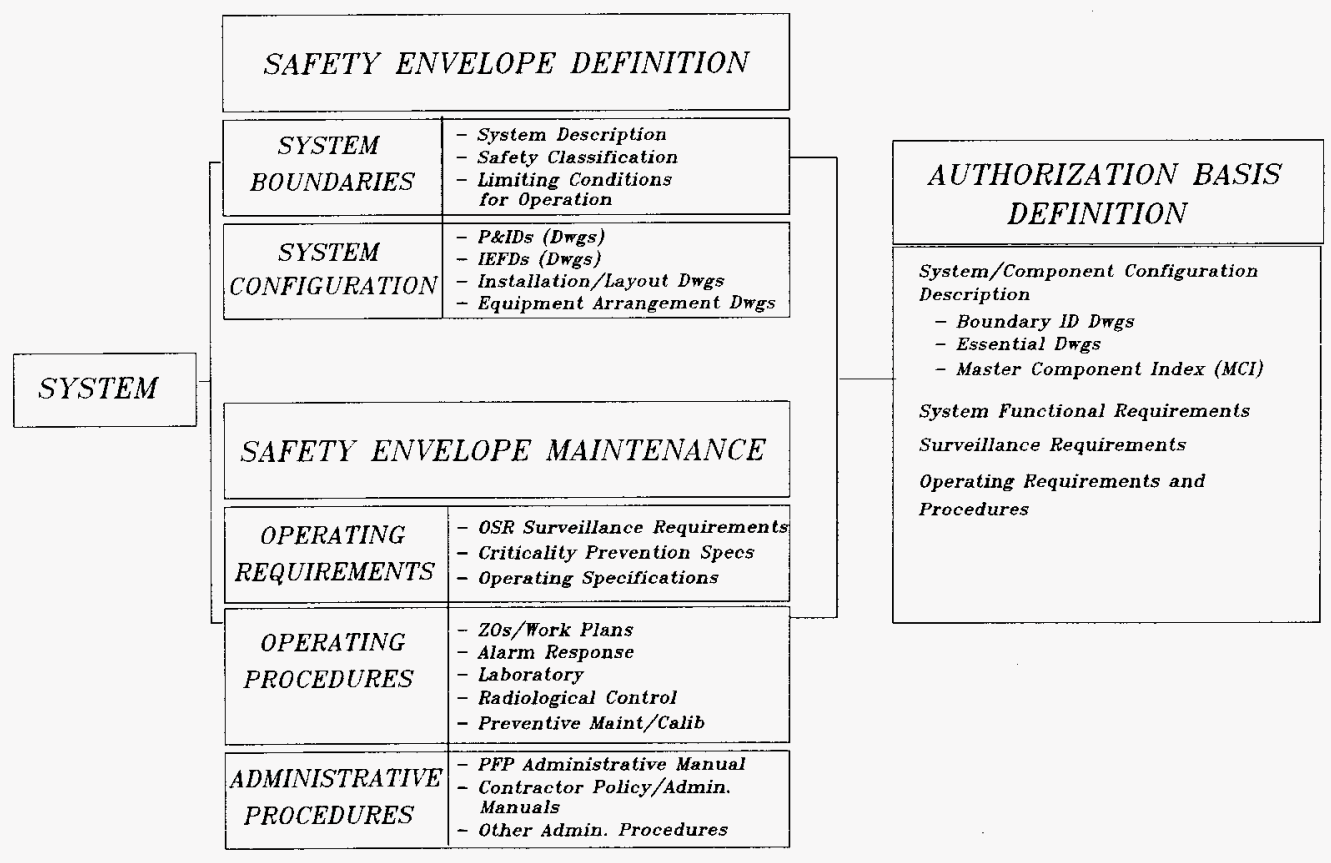


The maintenance and operating requirements for the systems, and the procedures that implement these requirements all comprise factors that provide for maintenance of the Safety Envelope. These requirements and procedures are also identified in the SDDs. Information sources for identifying the maintenance and operating requirements include:

- WHC-SD-CP-OSR-010, Plutonium Finishing Plant Operational Safety Requirements;

- Criticality Prevention Specification documents (operating requirements);

- Operating Specification Documents;

- WHC-CM-5-8, Plutonium Finishing Plant Administration, Volume 2, Section 13.3, "Operational Safety Requirements Compliance Program;

- Contractor Policy and Administration Manuals.

Implementing procedures are contained in the following working level documents:

- Safety envelope maintenance procedures (ZSEs), (written to explicitly demonstrate compliance with LCO SRs);

- Safety envelope related procedures (ZSRs);

- Plant Operating Procedures;

- Emergency Response Procedures;

- Laboratory Procedures;

- Radiological Control;

- Maintenance Procedures; 
- Administrative Procedures.

The SSCS and their relationship to the features and OSRs are explained in the following section.

\subsection{Identification of Safety Envelope SSCs}

Eight preventive or mitigative features provide the functions necessary to minimize the risks associated with identified events. Each of the eight preventive or mitigative features and the PFP SSC's which provide the feature is listed below. Where a SDD has been prepared or there is an associated OSR, that information is also provided. This information is summarized in Table 1. The numbers in the grid are abbreviated document numbers contained in the reference section and discussed below.

The first four features constitute the Safety Class Safety Envelope.

Feature 1 - Structural confinement boundaries necessary to prevent or mitigate the release of radioactive materials outside the facility. These features prevent or mitigate the effects of accidents such as those caused by earthquakes, strong wind, missiles of external origin (e.g. wind driven), explosion and fire. Portions of PFP building structures provide this feature. WHC-SD-CP-SDD-007, Definition and Means of Maintaining the Structural Confinement Portion of the PFP Safety Envelope, provides detailed definition of this portion of the PFP Safety Envelope. The SDD identifies specific SSCs such as walls, columns and steel structural members which provide this feature. Also identified are the bases for their selection and the survivability requirements for these structures. 
Related to Feature 1, in that it is used to minimize the release of radioactive materials outside of the facility in the event of a fire involving TRU containing waste drums stored outside of the facility, is $A C$ 5.24, Management of Transuranic Material Outside Facility Buildings. AC 5.24 establishes packaging requirements and implements outside $\mathrm{Pu}$ quantity storage limits required by FSAR Section 9.2.2D. The AC is implemented via Operations Specification Document 0SD-Z-184-00020, CH-TRU Solid Waste Disposal. Compliance is assured by periodic inspections made at the direction of the PFP Solid Waste Operations Manager.

Feature 2 - Ventilation confinement boundaries necessary to prevent or mitigate the release of radioactive materials outside the facility. These features prevent or mitigate releases of plutonium and other radioactive particulate contamination in the building ventilation exhaust stream. The ventilation exhaust filters for Zones 3 and 4 (Zones 1 and 2 in 2736-ZB) provide this confinement feature and are required by OSR LCO 3.2.1. WHC-SD-CP-SDD-005, Definition and Means of Maintaining the Ventilation System Confinement Portion of the PFP Safety Envelope, provides detailed definition of this portion of the PFP Safety Envelope. The SDD identifies specific filters and related SSCs which provide this feature, the bases for their selection, and their survivability requirements. 
Table 1 - SDD Cross Reference

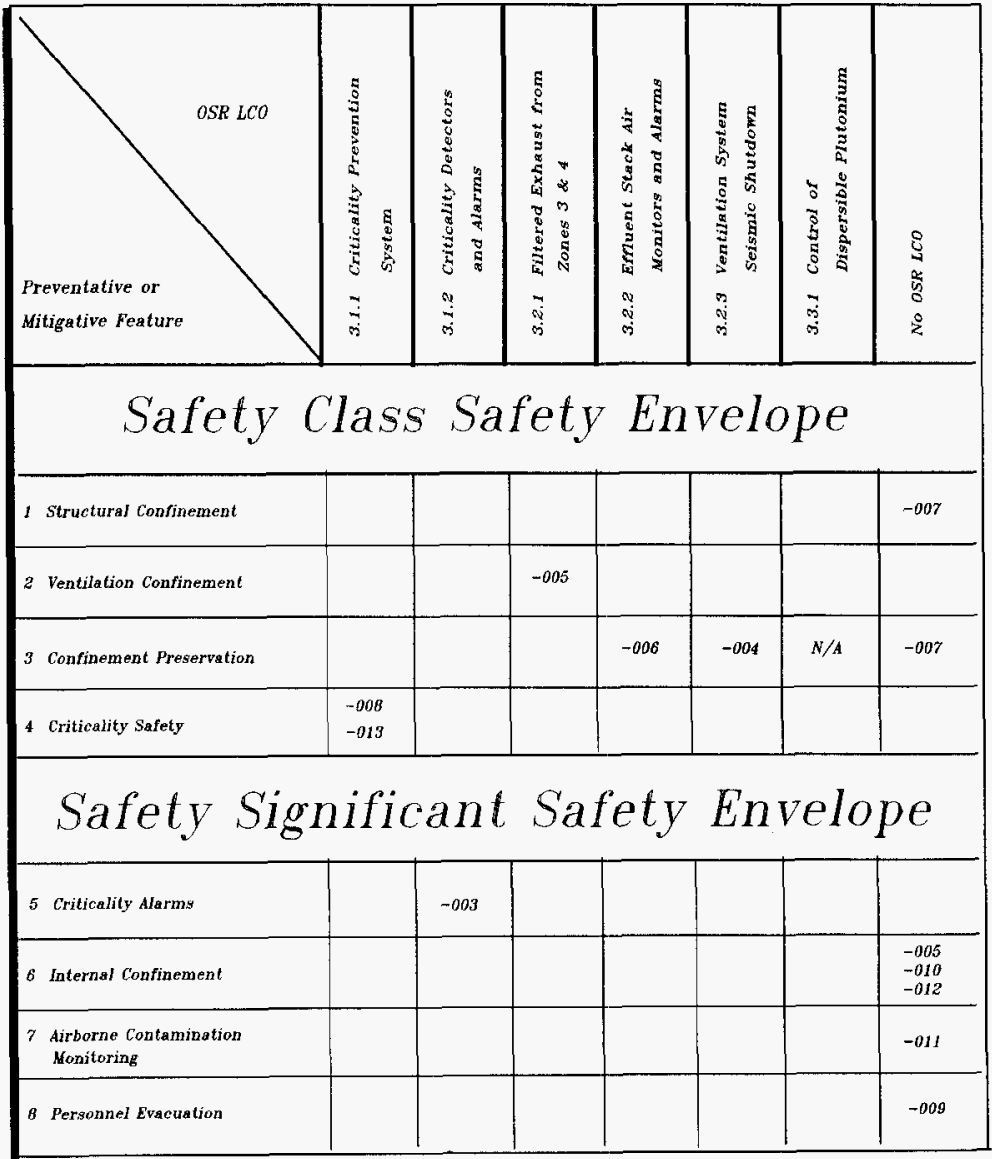




\section{Feature 3 - Equipment that prevents damage to structural or ventilation} confinement or is used to maintain or monitor integrity of the ventilation confinement boundary. This feature is provided to assure that features 1 and 2 are maintained intact through the various scenarios postulated in the FSAR. Several PFP SSCS provide this feature including:

- Seismic shutdown switch for the supply ventilation system; and

- Filter integrity monitoring and alarm equipment on exhaust stacks

Seismic studies have indicated that the 234-5Z building may experience some structural damage during an earthquake that could result in breaching of internal confinement barriers. Excessive release of radioactive particulate material to the environment could potentially occur if ventilation exhaust were lost but supply fans remained running. Therefore, an accelerometer activated electrical interlock system to shut down the 234-5Z ventilation supply fans and the glovebox dry air supply fans has been installed and is required by LCO 3.2.3. WHC-SD-CP-SDD-004, Definition and Means of Maintaining the Ventilation System Seismic Shutdown Portion of the PFP Safety Envelope, provides detailed definition of this portion of the PFP Safety Envelope. The SDD identifies the SSCs which provide this feature, the bases for their selection, and the definition of safety system boundaries.

The accident analyses in FSAR Chapter 9 have determined that an explosion of nitrated organics in any of several processing locations may potentially breach glovebox confinement. Had facility operating plans included operation of the Plutonium Reclamation Facility, solution temperatures would have been maintained below the level at which an explosion may have occurred, or the organic content of the solutions processed in these systems would have been controlled in order to have ensured that confinement boundaries were preserved. These systems are listed as inactive in the FSAR and will require a safety analysis and incorporation into the FSAR if future use of them is required. 
The effluent stack monitoring system does not directly provide a preventative or mitigative function, however, it does provide continuous sampling of the stack exhaust air stream and an early warning of a breach of ventilation confinement. This allows prompt mitigative action to be initiated, therefore, this system is considered part of the SC Safety Envelope. LCO 3.2.2 provides the requirement for the exhaust stack air monitors and alarms. WHC-SD-CP-SDD-006, Definition and Means of Maintaining the Effluent Stack Monitors and Samplers Portion of the PFP Safety Envelope, provides detailed definition of this portion of the PFP Safety Envelope. The SDD identifies the SSCs for each stack which provide this feature, the bases for their selection, and the definition of safety system boundaries.

In addition to the Safety Envelope SSCs, there are two OSR ACs that help to provide for feature 3 :

- Control of Flammable Gas Inventory; and

- Control of Dispersible Plutonium.

Administrative Control (AC) 5.21, Flammable Gas Inventory, is related to Feature 3 because of the potential for a flammable gas cylinder deflagration to breach the facility confinement. Since portable compressed gas cylinders are involved in this scenario rather than installed systems, control of the cylinders is required by an AC rather than a LCO. Compliance with $A C 5.21$ is assured by strictly controlling flammable gas type, number of cylinders, and cylinder size as specified in WHC-CM-5-8, Section 13.3, Operational Safety Requirements Compliance Program. 
Limitations on the total Pu inventory not contained in seismically resistant containers within PFP are specified in LCO 3.3.1. This LCO limits the amount and isotopic content of $\mathrm{Pu}$ potentially available for dispersal from the facility in severe accidents, thereby bounding the amount which could be released due to failure of the facility confinement boundaries. AC 5.22 provides additional control on the location and amount of dispersible (not in seismically resistant form or containers) $\mathrm{Pu}$ within the facility. This is necessary because the amount potentially released to the environment due to an accident is affected by the dispersible Pu's location within the facility. Compliance with LCO 3.3.1 is assured by the Criticality Safety Program and by conducting facility inspections as specified in WHC-CM-5-8, Section 13.3, Operational Safety Requirements Compliance Program.

Feature 4 - Equipment installed to provide a defined contingency utilized in the double contingency principle for prevention of nuclear criticality. The Criticality Safety program and facility Criticality Safety Evaluation Reports (CSERs) require that at least two unlikely, independent, and concurrent changes may occur without the $K_{\text {eff }}$ exceeding 0.95 . This is commonly referred to as the double contingency principle. Where practicable, one of these changes involves equipment design. Thus, any change in the design of this equipment requires review to ensure there is no decrease in the margin of safety. There are facility SSCs that provide at least one of the contingencies applied in the double contingency principle. These SSCs include the process vacuum $\left(26^{\mathrm{H}} \mathrm{Hg}\right.$ ) liquid detection shutdown interlock, selected criticality drains and sump fillers in solution handling gloveboxes, Room 166 sump Raschig rings, and Pu storage array configuration control. These items are included in the SC Safety Envelope. LCO 3.1.1 provides requirements for the control of these SSCs with exception of the storage arrays. Changes to $\mathrm{Pu}$ storage array design are controlled through the configuration management program and are subject to $A C$ 5.11, Unreviewed Safety Questions. With exception of storage arrays, WHC-SD-CP-SDD-008, Definition and Means of Maintaining the Criticality Prevention Design Features Portion of the PFP Safety Envelope and WHC-SD-CP-SDD-013, Definition and Means of Maintaining the Liquid Detection System, Process Vacuum Systems Portion of the PFP Safety Envelope, provide 
detailed definition of these portions of the PFP Safety Envelope. The SDDs identify SSCS which provide these features, the bases for their selection, and the definition of safety system boundaries.

The remaining four features found in FSAR Chapter 9 constitute the SS Safety Envelope.

Feature 5 - Alarm systems used to evacuate personnel in the event of a nuclear criticality. This feature minimizes potential radiation exposure of personnel by providing timely detection of a criticality and initiating an evacuation alarm. LCO 3.1.2, Criticality Detectors and Alarms, provides requirements for the operability of the Criticality Alarm System. WHC-SD-CP-SDD-003, Definition and Means of Maintaining the Criticality Detectors and Alarms Portion of the PFP Safety Envelope, provides detailed definition of this portion of the PFP Safety Envelope. The SDD identifies the SSCS which provide this feature, the bases for their selection, and the definition of the safety system boundaries.

Feature 6 - Internal confinement provided by established facility ventilation zones to prevent the spread of contamination within the facility, and systems related to fire protection, whose failure could result in grossly jeopardizing facility worker safety.

Two PFP SSCs provide this feature including:

- Building ventilation equipment which maintains negative pressures in highly contaminated areas; and

- Fire detection and suppression equipment. 
Portions of building ventilation systems provide control of the differential pressures between the various ventilation zones so the highly-contaminated Zone 4 (Zone 1 in 2736-ZB) is always negative with respect to the occupied zones, thus minimizing the spread of radiological contamination and ensuring safety of the facility workers. WHC-SD-CP-SDD-005, Definition and Means of Maintaining the Ventilation System Confinement Portion of the PFP Safety Envelope, provides detailed definition of this portion of the PFP Safety Envelope. The SDD also identifies the components of the ventilation system which do not provide this function in order to define safety system boundaries.

Fire detection and suppression equipment is installed primarily to prevent injury of facility personnel due to burns and toxic gas, radiological contamination within the facility from breached gloveboxes, and property loss. Although discussed in a consequence bounding accident scenario, the fire protection system functions are not essential to preserving the building confinement safety envelope. In a SS Safety Envelope context the fire protection system provides for worker safety and minimize challenges to the confinement within the facility thus adding additional assurance that unacceptable doses to facility personnel would not occur. WHC-SD-CP-SDD-010, Definition and Means of Maintaining the Fire Protection System Portion of the PFP Safety Envelope, provides detailed definition of this portion of the PFP Safety Envelope.

Feature 7 - Equipment used to warn personnel of airborne contamination in facility working areas. These features prevent or mitigate inhalation of radionuclide contamination by the facility workers by providing timely audible and visual alarms. WHC-SD-CP-SDD-011, Definition and Means of Maintaining the Room Continuous Air Monitors Portion of the PFP Safety Envelope, provides detailed definition of the portion of the PFP Safety Envelope including definition of safety system boundaries. 
Feature 8 - Equipment provided for safe evacuation of facility personnel in case of emergency. These features facilitate personnel safety by providing for evacuation notification and ensuring that egress can be performed safely and promptly in the event of emergencies such as loss of ventilation, loss of power, etc. While not required by an OSR, FSAR Chapter 9 addresses the notification and evacuation features that function in a Safety Envelope context to minimize the risk to personnel in the event an emergency. WHC-SD-CP-SDD-009, Definition and Means of Maintaining the Plant Evacuation System (PAX and Evacuation Siren) Portion of the PFP Safety Envelope, provides detailed definition of this portion of the PFP Safety Envelope. 


\subsection{References}

Safety of Nuclear Facilities, DOE 5480.5, US Department of Energy, Washington, D.C.

Unreviewed Safety Question, DOE 5480.21, US Department of Energy, Washington, D.C.

Technical Safety Requirements, DOE 5480.22, US Department of Energy, Washington, D.C.

Nuclear Safety Analysis Reports, D0E 5480.23, US Department of Energy, Washington, D.C.

Preparation Guide for U.S. Department of Energy Nonreactor Nuclear Facility Safety Analysis Reports, DOE-STD-3009-94, U.S. Department of Energy, Washington, D.C., (DOE 1994).

WHC-SD-CP-FSAR-021, Rev. 0, Plutonium Finishing Plant Final Safety Analysis Report, Westinghouse Hanford Company, Richland, Washington.

WHC-SD-CP-0SR-010, Rev. 0, Plutonium Finishing Plant Operational Safety Requirements, Westinghouse Hanford Company, Richland Washington.

Standard Arch - Civil Design Criteria - Design Loads for Facilities, Hanford Plant Standards SDC-4.1, Rev. 11, U.S. Department of Energy - Richland Field office, Richland, Washington

WHC-CM-4-29, Nuclear Criticality Safety Manual, Westinghouse Hanford Company, Richland, Washington.

WHC-CM-5-8, Plutonium Finishing Plant Administration, Westinghouse Hanford Company, Richland, Washington.

WHC-SD-CP-SDD-003, Definition and Means of Maintaining the Criticality Detectors and Alarms Portion of the PFP Safety Envelope. 
WHC-SD-CP-SDD-004, Definition and Means of Maintaining the Ventilation System Seismic Shutdown Portion of the PFP Safety Envelope.

WHC-SD-CP-SDD-005, Definition and Means of Maintaining the Ventilation System Confinement Portion of the PFP Safety Envelope.

WHC-SD-CP-SDD-006, Definition and Means of Maintaining the Effluent Stack Monitors Portion of the PFP Safety Envelope.

WHC-SD-CP-SDD-007, Definition and Means of Maintaining the Structural Confinement Features Portion of the PFP Safety Envelope.

WHC-SD-CP-SDD-008, Definition and Means of Maintaining the Criticality Prevention Design Features Portion of the PFP Safety Envelope.

WHC-SD-CP-SDD-009, Definition and Means of Maintaining the Plant Evacuation System (PAX, and Evacuation Siren) Portion of the PFP Safety Envelope.

WHC-SD-CP-SDD-010, Definition and Means of Maintaining the Fire Protection System Portion of the PFP Safety Envelope.

WHC-SD-CP-SDD-011, Definition and Means of Maintaining the Room Continuous Air Monitors Portion of the PFP Safety Envelope.

WHC-SD-CP-SDD-012, Definition and Means of Maintaining the Product Concentrator and Filtrate Evaporator Portion of the PFP Safety Envelope.

WHC-SD-CP-SDD-013, Definition and Means of Maintaining the Liquid Detection System, Process Vacuum Systems Portion of the PFP Safety Envelope.

WHC-SD-CP-TI-108, PFP Safety Equipment List.

WHC-SD-CP-TI-125, Essential and Support Drawing List. 


\section{DISTRIBUTION SHEET}

\begin{tabular}{|c|c|c|c|c|c|c|}
\hline \multirow{2}{*}{\multicolumn{2}{|c|}{$\begin{array}{l}\text { To } \\
\text { Distribution }\end{array}$}} & \multirow{2}{*}{\multicolumn{3}{|c|}{$\begin{array}{l}\text { From } \\
\text { J. P. King }\end{array}$}} & \multicolumn{2}{|c|}{ Page 1 of 1} \\
\hline & & & & & \multicolumn{2}{|c|}{ Date $2 / 25 / 97$} \\
\hline \multirow{2}{*}{\multicolumn{5}{|c|}{$\begin{array}{l}\text { Project Title/Work Order } \\
\text { Authorization Basis for PFP, FSAR/OSR }\end{array}$}} & \multirow{2}{*}{\multicolumn{2}{|c|}{$\begin{array}{ll}\text { EDT No. } & \text { N/A } \\
\text { ECN No. } & 631098\end{array}$}} \\
\hline & & & & & & \\
\hline \multicolumn{3}{|c|}{ Name } & $\begin{array}{l}\text { Text } \\
\text { With All } \\
\text { Attach. }\end{array}$ & Text Only & $\begin{array}{l}\text { Attach./ } \\
\text { Appendix } \\
\text { Only }\end{array}$ & $\begin{array}{l}\text { EDT/ECN } \\
\text { Only }\end{array}$ \\
\hline $\begin{array}{l}\text { G. G. } \\
\text { J. D. } \\
\text { L. E. } \\
\text { M. W. } \\
\text { G. A. } \\
\text { J. M. } \\
\text { J. P. } \\
\text { C. M. } \\
\text { E. M. } \\
\text { D. J. } \\
\text { C. A. } \\
\text { R. D. } \\
\text { A. L. } \\
\text { H. E. } \\
\text { W. D. } \\
\text { M. D. } \\
\text { D. W. }\end{array}$ & $\begin{array}{l}\text { Bergquist } \\
\text { Dick } \\
\text { Edvalson } \\
\text { Gibson } \\
\text { Glover } \\
\text { Held } \\
\text { King } \\
\text { Kronvall } \\
\text { LaRock } \\
\text { McBride } \\
\text { Meldrom } \\
\text { Redekopp } \\
\text { Ramble } \\
\text { Rew } \\
\text { Seaborg } \\
\text { Talbot } \\
\text { Templeton }\end{array}$ & $\begin{array}{l}\text { T5-55 } \\
\text { T4-20 } \\
\text { T5-48 } \\
\text { T5-55 } \\
\text { T4-20 } \\
\text { T5-11 } \\
\text { T5-51 } \\
\text { T5-53 } \\
\text { T5-02 } \\
\text { T5-54 } \\
\text { T5-02 } \\
\text { T5-15 } \\
\text { T5-54 } \\
\text { T4-15 } \\
\text { T5-50 } \\
\text { T5-15 } \\
\text { R3-79 }\end{array}$ & $\begin{array}{l}x \\
X \\
X \\
X \\
X \\
X \\
X \\
X \\
X \\
X \\
X \\
X \\
X \\
X \\
X \\
X \\
X\end{array}$ & & & \\
\hline
\end{tabular}

